\title{
Crystal Structure and Electrical Properties of $\mathrm{La}_{0.45} \mathrm{Ce}_{0.1} \mathrm{Li}_{0.27} \mathrm{TiO}_{3}$ Synthesized by Sol-Gel Technique
}

\author{
Néstor Fernández ${ }^{1}$, Purificación Escribano², Eloisa Cordoncillo², Héctor Beltrán², \\ Mario F. García-Sánchez ${ }^{3}$, Issis C. Romero-Ibarra ${ }^{4}$, Nahum Masó ${ }^{2}$
}

${ }^{1}$ Departamento de Química Inorgánica, Facultad de Química, Universidad de la Habana, Ciudad de la Habana, Cuba; ${ }^{2}$ Departament de Química Inorgánica i Orgánica, Universitat Jaume I, Castellón, España; ${ }^{3}$ Unidad Profesional Interdisciplinaria en Ingeniería y Tecnologías Avanzadas, Instituto Politécnico Nacional (IPN), México D.F., México; ${ }^{4}$ Departamento de Reología, Instituto de Investigaciones en Materiales, Universidad Nacional Autónoma de México, México D.F., México.

Email: rusonil@yahoo.com

Received November $26^{\text {th }}, 2011$; revised December $20^{\text {th }}, 2011$; accepted December $30^{\text {th }}, 2011$

\begin{abstract}
The lithium ionic conducting $\mathrm{La}_{0.43} \mathrm{Ce}_{0.1} \mathrm{Li}_{0.27} \mathrm{TiO}_{3}$ has been synthesized by sol-gel method. This solid is the result of substitutional doping with $\mathrm{Ce}(\mathrm{IV})$ in $\mathrm{La}_{0.57} \mathrm{Li}_{0.27} \mathrm{TiO}_{3}$ compound. The aim of the replacement of $\mathrm{La}$ (III) by $\mathrm{Ce}(\mathrm{IV})$ is increase the number of vacancies in the structure and favors the ionic mobility. Structural characterization shows that the obtained material have the expected tetragonal $\mathrm{P} 4 / \mathrm{mmm}$ perovskite structure. Chemical analysis shows that composition was homogeneus in all the sample. The bulk conductivity measured at room temperature is about the same as previously reported for its related lanthanum lithium titanate. However, the lower activation energy for ionic conduction encourages further searching for better conductors in this system.
\end{abstract}

Keywords: Lithium Ion Conductors; Sol Gel; Impedance Spectroscopy; Perovskite

\section{Introduction}

Fast lithium ion conductors with the general formula $\mathrm{RE}_{0.66-\mathrm{x}} \mathrm{Li}_{3 \mathrm{x}} \mathrm{TiO}_{3}$ (RE: La, Pr, Nd, Sm) have been intensively studied since the last decade [1-9]. The materials were prepared mainly by ceramic methods and showed perovskite-like crystal structure. The presence of RE(III) in the perovskite A-site causes the existence of vacancies in the crystal structure and allows lithium ion to move through the solid leading to a DC conduction. The maximum bulk conductivity found at room temperature in this kind of solids was $1.1 \times 10^{-3} \mathrm{~S} \cdot \mathrm{cm}^{-1}$ for lanthanum lithium titanate system (LLTO) $\mathrm{La}_{0.66-\mathrm{x}} \mathrm{Li}_{3 \mathrm{x}} \square_{1 / 3-2 \mathrm{x}} \mathrm{TiO}_{3}$ with $\mathrm{x}=0.11$, which results is the better compromise between number of vacancies and lithium ions [2,3]. In this equation, $\square$ represents the number of vacancies. Substitution of other RE for A-site La always results in lower bulk conductivity. This fact has been related to the shortening of cell parameters found as a result of the smaller substitute cation ionic radius [9]. Many other related systems were prepared by substitutional doping for RE or Ti [10-12]. As a rule, none of these related solids improves the maximum conductivity value previously reported.

The accepted conduction mechanism consists on hopping lithium ions from its lattice site to adjacent vacancy across the so called "bottleneck" formed by four $\mathrm{TiO}_{6}$ octahedra [8-10]. The reduction of cell parameters shrinks the bottleneck and raises the activation barrier for ionic movement. Conductivity values for these solids depend on the number of ionic charge carriers and the number of vacancies as well.

Crystal radii for $\mathrm{Ce}(\mathrm{IV})$ and $\mathrm{La}(\mathrm{III})$ in 12-coordination are reported by Sannon as $1.28 \AA$ and $1.50 \AA$ respecttively [13]. This value is in the borderline of the usually accepted $15 \%$ size difference limiting range for substitution without disrupting the structure [14]. It follows that $\mathrm{Ce}(\mathrm{IV})$ could substitute La(III) in LLTO A-site. Substitution of $\mathrm{Ce}(\mathrm{IV})$ for $\mathrm{La}(\mathrm{III})$ creates additional vacancies and must facilitate the ionic diffusion movement through the solid and improves its conduction properties, despite of the expected bottleneck shrinkage effect.

The sol-gel method preparation for precursor powders was chosen owing to its known lower reacting and sintering temperature and time. In addition, the materials synthesized by this method have uniform particles size and shape. These features are expected that improve the total material conductivity $[15,16]$.

This paper discusses the preparation of $\mathrm{Ce}(\mathrm{IV})$ substitutional doped perovskite-like solid $\mathrm{La}_{0.45} \mathrm{Ce}_{0.1} \mathrm{Li}_{0.27} \mathrm{TiO}_{3}$ via sol-gel and its structural and electrical characteriza- 
tion. This solid could be considered as a member of the hypothetical series $\mathrm{La}_{0.66-\mathrm{x}-\mathrm{y}} \mathrm{Ce}_{0.75 \mathrm{y}} \mathrm{Li}_{3 \mathrm{x}} \mathrm{TiO}_{3}$ with $\mathrm{x}=0.09$ and $y=0.133$. This material have the same lithium content that the equivalent material without $\mathrm{Ce}$ (i.e. $\mathrm{La}_{0.57}$ $\mathrm{Li}_{0.27} \square_{0.153} \mathrm{TiO}_{3}$ ), but the number of vacancies is about $20 \%$ higher (0.187).

\section{Experimental Section}

The synthesis was carried out by sol-gel technique. $5 \mathrm{ml}$ ethanol (99.8\% Scharlau), $16.74 \mathrm{~g} \mathrm{Ti(isoO-Pr})_{4}(98 \%$ Strem Chemicals) and $6.07 \mathrm{~g}$ acac (99.5\% Panreac) were placed in a beaker with continuous stirring. Thereafter, another solution with $8 \mathrm{ml}$ ethanol, $11.11 \mathrm{~g} \mathrm{La}\left(\mathrm{NO}_{3}\right)_{3}$. $6 \mathrm{H}_{2} \mathrm{O}\left(99.9 \%\right.$ Strem), $3.16 \mathrm{~g}\left(\mathrm{NH}_{4}\right)_{2}\left[\mathrm{Ce}\left(\mathrm{NO}_{3}\right)_{6}\right](99.9 \%$ Strem) and $1.07 \mathrm{~g} \mathrm{LiNO}_{3}(99 \%$ Strem) was added to the previous one. The solvent was evaporated during three days below IR lamp and the obtained gel was thoroughly dried in the oven at $100^{\circ} \mathrm{C}$. The dried gel was ground up in aghata mortar, placed into alumina crucible and heated at $2^{\circ} \mathrm{C} / \mathrm{min}$ up to $500^{\circ} \mathrm{C}$. This temperature was maintained for $2 \mathrm{~h}$ to complete the decomposition of organic precursors in the sample. The precursor powder obtained was ground up, pressed into $13 \mathrm{~mm}$ disk pellets and placed in Pt crucibles. The sample was covered with isocompositional powder and closed with Pt foil in order to prevent evaporation of lithium compounds $[12,15,17-$ 19]. The sample was heated for reacting and sintering at $15^{\circ} \mathrm{C} / \mathrm{min}$ up to $1100^{\circ} \mathrm{C}$, at which temperature stood for 2 hours. Then it was slowly cooled to room temperature during about 10 hours.

Phase identification was done by X-ray diffraction (XRD) in a Siemens D-500 diffractometer using $\mathrm{Cu} \mathrm{K}_{\alpha}$ radiation. Scanning electron microscopy (SEM) and energy dispersive X-ray spectroscopy (EDS) analysis were performed in an Oxford Instrument LEO 440i microscope. AC electrical measurements were performed from room temperature up to $300^{\circ} \mathrm{C}$ in air using an $\mathrm{HP} 4192$ Impedance analyser over the frequency range $100 \mathrm{~Hz}-13$ MHz. Samples for electrical measurements were prepared from the pellets as they came out from synthesis, coated with gold paste and assembled between Pt electrodes. Dimensions of samples were measured with 0.01 $\mathrm{mm}$ precision caliper and they were weighted with $0.0001 \mathrm{~g}$ precision.

\section{Results and Discussion}

Figure 1 shows the XRD pattern obtained from solid sample. The obtained peaks were indexed according to PDF 87 - 936 with reports parameters of $\mathrm{P} 4 / \mathrm{mmm}$ tetragonal perovskite-like structure. Similar results were obtained in compounds without cerium synthesized by sol gel [16]. The phase tetragonal is usually found in compounds obtained by this method due to the low tem-

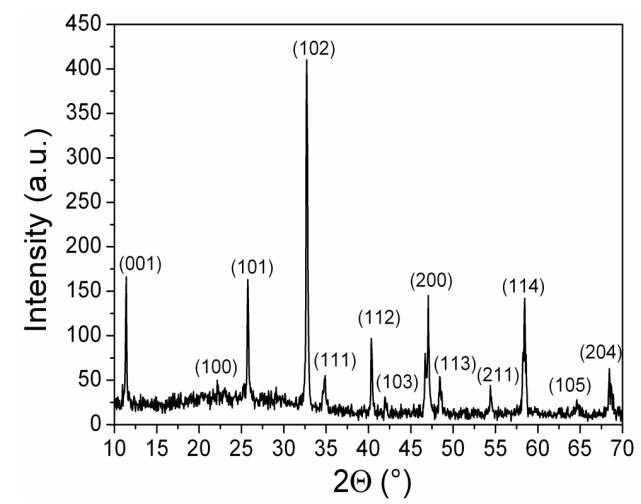

Figure 1. XRD pattern form $\mathrm{La}_{0.45} \mathrm{Ce}_{0.1} \mathrm{Li}_{0.27} \mathrm{TiO}_{3}$.

peratures of synthesis $[15,16]$. Secondary phases can not be identified. The lattice parameters calculated from XRD data are: $\mathrm{a}=3.8583(9) \AA$ and $\mathrm{c}=7.739(2) \AA$. The reported values for the related LLTO with $\mathrm{x}=0.09$ are: a $\approx 3.87 \AA$ and $\mathrm{c} \approx 7.74 \AA[3,20,21]$. The apparent smaller unit cell size for the Ce(IV) doped LLTO compared to the undoped one is in agreement with the expected effect caused by the replacement for $\mathrm{La}(\mathrm{III})$ by the smaller cation $\mathrm{Ce}(\mathrm{IV})$.

Theoretical density calculated from these cell parameters as $5.010 \mathrm{~g} \cdot \mathrm{cm}^{-3}$, and the experimentally calculated value was $4.258 \mathrm{~g} \cdot \mathrm{cm}^{-3}$ (85.5\% from theoretic). The rather low density achieved for this material is usual for sol-gel samples, due to the low temperature and short time of sintering step.

Figure 2 shows SEM images from sintered disk. It can be seen the rounded particle shape, uniform particle size, and the high porosity nature of sample. The last feature agrees with the low experimental density found. The mean particle size, estimated from 50 randomly selected particles, is $(1.3 \pm 0.3) \mu \mathrm{m}$. All these observed morphological features are consistent with the expected properties of a solid obtained from a sol-gel method.

The EDS analysis performed on several points on the sample showed good compositional homogeneity and a ratio of elements: Ti:Ce:La $=1: 0.1: 0.49$; which correspond fairly well with nominal composition. This correspondence in the calculated ratios and the nominal composition suggest that $\mathrm{Ce}$ remains with the $4+$ oxidation state. Moreover, the presence of different oxidation states of Ce change the color of sample to dark [17].

Figure 3 shows an impedance plot measured at $20^{\circ} \mathrm{C}$, where three different processes can be observed. The two higher frequency processes were modeled with semicircles. The semicircle centers are clearly depressed below the baseline, indicating a non-Debye response in this material, as usual in other ionic conductors [12,22-26].

The third process in Figure 3 can be simulated with another semicircle or with a line (spike). The difference is due to the kind of process (conductive or dielectric) and 


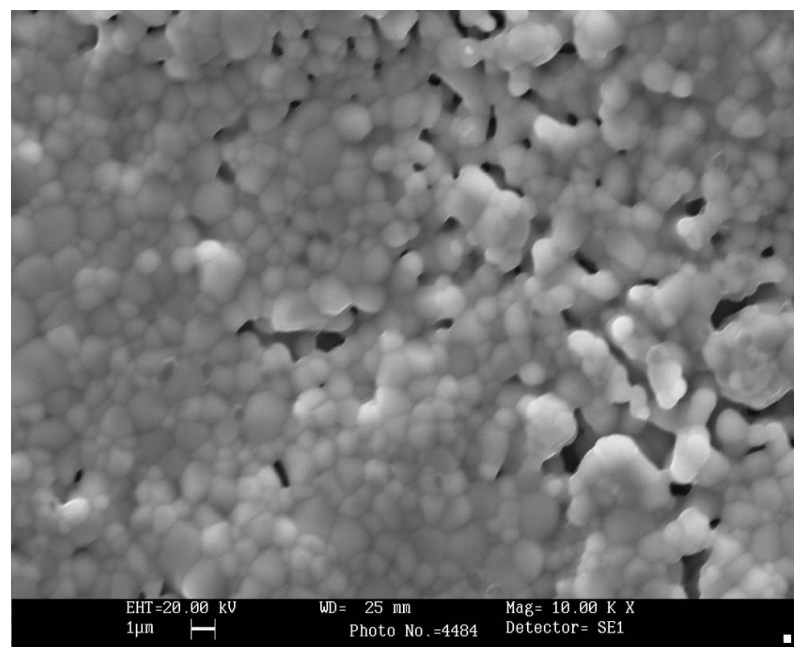

Figure 2. SEM image from sintered $\mathrm{La}_{0.45} \mathrm{Ce}_{0.1} \mathrm{Li}_{0.27} \mathrm{TiO}_{3}$.

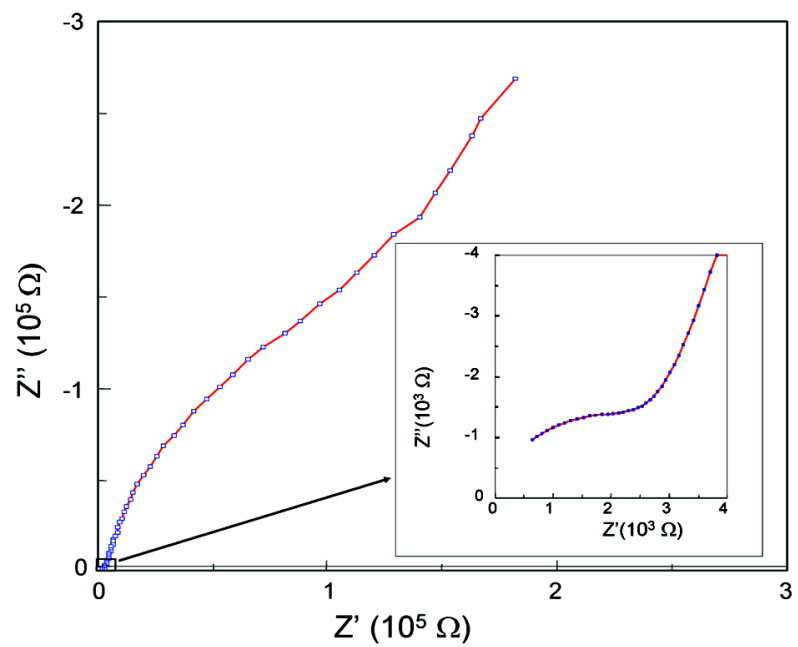

Figure 3. Complex impedance plot for $\mathrm{La}_{0.45} \mathrm{Ce}_{0.1} \mathrm{Li}_{0.27} \mathrm{TiO}_{3}$ at $20^{\circ} \mathrm{C}$.

it must be defined before to select the equivalent circuit.

Figure 4 shows the admitance plot for sample measured at $20^{\circ} \mathrm{C}$. It is well known that conductive process have an admitance value different of cero at cero frequency [22]. As the admitance plot begin in cero, the third process is unambigous associated to a dielectric process and simulated with a spike. Then, the electric behavior of sample was modeled with an equivalent circuit comprising a set of a capacitor, resistance and CPE (constant phase element) in parallel for each semicircle [22,23,27] and an additional CPE element for modelling the spike, all in series between them. All fitting was processed by using the Zview software package [28].

Figure 5 shows the equivalent circuit used and the simulated values obtained for sample presented in Figures 3 and 4 . The capacities obtained values are about $10^{-12} \mathrm{~F}$ and $10^{-9} \mathrm{~F}$ for high and low frequency semicircles respectively. From these values the responses can be as-

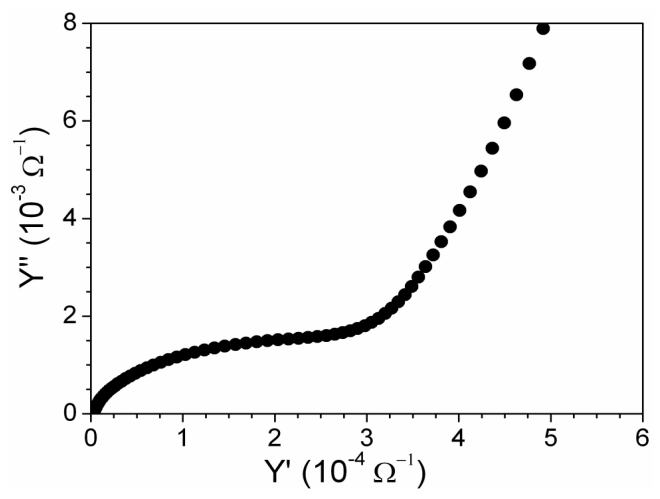

Figure 4. Complex admitance plot for $\mathrm{La}_{0.45} \mathrm{Ce}_{0.1} \mathrm{Li}_{0.27} \mathrm{TiO}_{3}$ at $20^{\circ} \mathrm{C}$.

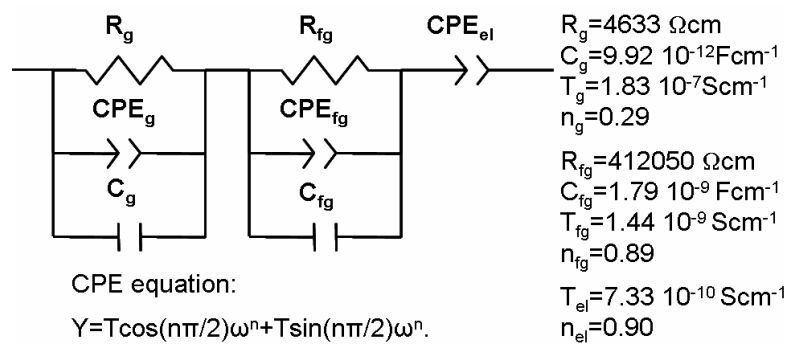

Figure 5. Equivalent circuit and fitting results of AC data for $\mathrm{La}_{0.45} \mathrm{Ce}_{0.1} \mathrm{Li}_{0.27} \mathrm{TiO}_{3}$ at $20^{\circ} \mathrm{C}$.

sociated to bulk and grain boundary behavior respecttively [22]. The spike could be ascribed to a low conductivity layer on the pellet surface as it has been reported for similar materials [23].

Conductivities at different temperatures were calculated from resistance values of the modeled circuit. The temperature-conductivity data fit very well an Arrhenius format as is shown in Figure 6. The conductivity at $25^{\circ} \mathrm{C}$ and the activation energy (Ea) were calculated for grain and grain boundary from these graphics.

Table 1 discloses the conductivity and the activation energy at $25^{\circ} \mathrm{C}$ for $\mathrm{La}_{0.45} \mathrm{Ce}_{0.1} \mathrm{Li}_{0.27} \mathrm{TiO}_{3}$.

It is important to note that the activation energy $\mathrm{Ea}=$ $0.29 \mathrm{eV}$ is lower than the value $0.37 \mathrm{eV}$ reported by Bohnke et al. [21] in the range $200-400 \mathrm{~K}$ and also lower than $0.36 \mathrm{eV}$, which was reported by Itoh et al. [29] for LLTO with its optimum conducting composition $\mathrm{x}=$ 0.11 and cubic structure. The activation energy is related with the bottleneck [30]. In compounds with partially occupied sites, abnormally large cation-anion distances are usually found, as expected if the anions surrounding unoccupied sites relax toward their bonded cation neighbours. Therefore average distances should increase as the occupancy factor decreases. In this way the bottleneck around the vacancies is higher although the cell volume is lower as average. Another aspect in the activetion energy is the electrostatic interaction in the surrounding of lithium. The partial substitution of Bismuth 


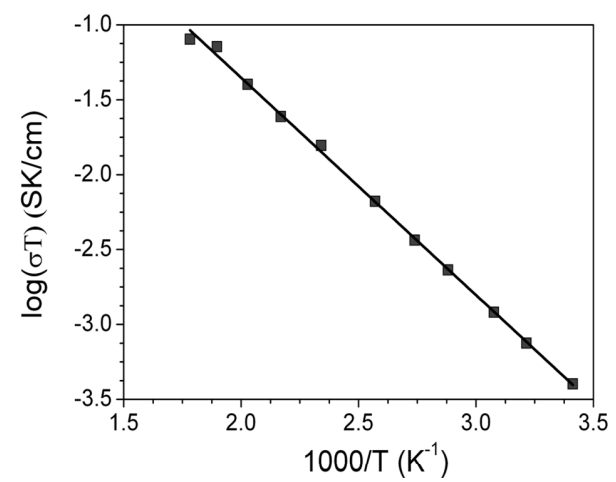

(a)

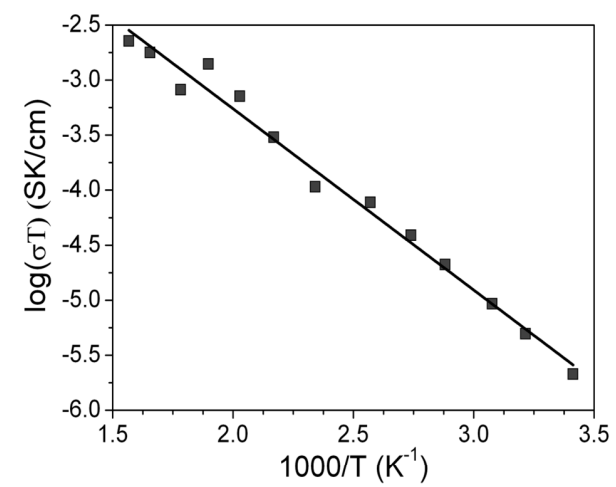

(b)

Figure 6. Arrehnius plots for $\mathrm{La}_{0.45} \mathrm{Ce}_{0.1} \mathrm{Li}_{0.27} \mathrm{TiO}_{3}$ : (a) bulk and (b) grain boundary.

Table 1. Conductivity at $25^{\circ} \mathrm{C}\left(\sigma_{\mathrm{RT}}\right)$ and activation energy values (Ea) for $\mathrm{La}_{0.45} \mathrm{Ce}_{0.1} \mathrm{Li}_{0.27} \mathrm{TiO}_{3}$.

\begin{tabular}{ccc}
\hline & $\sigma_{\mathrm{RT}}\left(\mathrm{S} \cdot \mathrm{cm}^{-1}\right)$ & $\mathrm{Ea}(\mathrm{eV})$ \\
\hline Bulk & $4.67 \times 10^{-4}$ & 0.29 \\
Grain boundary & $3.46 \times 10^{-6}$ & 0.33 \\
\hline
\end{tabular}

in this compounds do not change the cell parameters, but decrease the lithium conductivity. More experimental research or computational simulation is necessary in order to clarify this behaviour.

The obtained bulk conductivity at $25^{\circ} \mathrm{C}\left(\sigma_{\mathrm{RT}}\right)$ of $\mathrm{Ce}(\mathrm{IV})$ doped solid $\left(4.67 \times 10^{-4} \mathrm{~S} \cdot \mathrm{cm}^{-1}\right)$ is in order of the maximum value previously reported for tetragonal LLTO with $\mathrm{x}=0.1$, which varies between $1.1 \times 10^{-3}$ [3] or $3.9 \times 10^{-4}$ $\mathrm{S} \cdot \mathrm{cm}^{-1}[21]$. For increasing this conductivity value must be higher the concentration of carriers, in this case, lithium ions [17]. These results suggest that rising the $\mathrm{Li}$ content in the composition of Ce(IV) doped solid, if it was permitted by the nature of solid solution in this system, the conduction property of material could be improved.

The conductivity value encountered for the grain boundary is lower than the bulk conductivity reported for LLTO [10]. This is actually one of the limiting facts in order to practical application of this kind of materials. In general, this value is higher in sol-gel obtained samples than in ceramic obtained samples [15]. The activation energy is slightly higher than in grains, which is related with the fact of the grain boundary is a very defective region $[11,12]$. Anyway, this value is lower than reported in related systems, which suggest that the optimization of this system can result in low conductivity materials. Further experiments in this direction are now in progress.

\section{Conclusion}

$\mathrm{La}_{0.43} \mathrm{Ce}_{0.1} \mathrm{Li}_{0.27} \mathrm{TiO}_{3}$ has been synthesized by sol-gel method. XRD shows the $\mathrm{P} 4 / \mathrm{mmm}$ tetragonal perovskite structure and secondary phases are not present. The experimental composition is homogeneus and corresponds fairly well with nominal composition. An uniform grain size of $(1.3 \pm 0.3) \mu \mathrm{m}$ was observed. The bulk conductiveity measured at $25^{\circ} \mathrm{C}$ for the obtained solid is similar as previously reported for its related lanthanum lithium titanate. However, this parameter can be increased with the increase of lithium concentration. The activation energy for ionic conduction is lower than the obtained in similar systems, which suggest the potentialities of this material in the search of better lithium conductors at room temperature. The grain boundary conductivity must be increase in order to practical applications.

\section{REFERENCES}

[1] A. G. Belous, G. N. Novitskaya, S. V. Polyanetskaya and Y. I. Gornikov, "Crystal-Chemical and Electrical-Physical Characteristics of $\mathrm{Ln}_{(2 / 3-x)} \mathrm{M}_{3 \mathrm{x}} \mathrm{TiO}_{3}$ Complex Oxides," Zhurnal Neorganicheskoi Khimii, Vol. 32, No. 2, 1987, pp. 283-286.

[2] Y. Inaguma, C. Liquan, M. Itoh, T. Nakamura, T. Uchida, H. Ikuta and M. Wakihara, "High Ionic Conductivity in Lithium Lanthanum Titanate," Solid State Communications, Vol. 86, No. 10, 1993, pp. 689-693. doi:10.1016/0038-1098(93)90841-A

[3] H. Kawai and J. Kuwano, "Lithium Ion Conductivity of A-Site Deficient Perovskite Solid Solution $\mathrm{La}_{0.67-\mathrm{x}} \mathrm{Li}_{3 x^{-}}$ $\mathrm{TiO}_{3}$," Journal of The Electrochemical Society, Vol. 141, No. 7, 1994, pp. L78-L79. doi:10.1149/1.2055043

[4] M. Morales and A. R. West, "Phase Diagram, Crystal Chemistry and Lithium Ion Conductivity in the Perovskite-Type System $\mathrm{Pr}_{0.5+\mathrm{x}} \mathrm{Li}_{0.5-3 \mathrm{x}} \mathrm{TiO}_{3}$," Solid State Ionics, Vol. 91, No. 1-2, 1996, pp. 33-43. doi:10.1016/S0167-2738(96)00420-1

[5] A. D. Robertson, S. García-Martín, A. Coats and A. R. West, "Phase Diagrams and Crystal Chemistry in the $\mathrm{Li}^{+}$ Ion Conducting Perovskites, $\mathrm{Li}_{0.5-3 x} \mathrm{RE}_{0.5+3 \mathrm{x}} \mathrm{TiO}_{3}: \mathrm{RE}=\mathrm{Pr}$, Nd," Journal of Materials Chemistry, Vol. 5, No. 9, 1995, pp. 1405-1412. doi:10.1039/jm9950501405

[6] A. I. Ruiz, M. L. López, M. L. Veiga and C. Pico, "Electrical Properties of $\mathrm{La}_{1.33-\mathrm{x}} \mathrm{Li}_{3 \mathrm{x}} \mathrm{Ti}_{2} \mathrm{O}_{6}(0.1<\mathrm{x}<0.3)$," 
Solid State Ionics, Vol. 112, No. 3-4, 1998, pp. 291-297. doi:10.1016/S0167-2738(98)00220-3

[7] E. A. Fortal'nova, O. N. Gavrilenkov, A. G. Belous and E. D. Politova, "Lithium-Ion Conducting Oxides: Synthesis, Structure, and Electroconducting Properties," Russian Journal of General Chemistry, Vol. 79, No. 9, 2009, pp. 1987-1997. doi:10.1134/S1070363209090308

[8] P. Knauth, "Inorganic Solid Li Ion Conductors: An Overview," Solid State Ionics, Vol. 180, No. 14-16, 2009, pp. 911-916. doi:10.1016/j.ssi.2009.03.022

[9] O. Bohnke, "The Fast Lithium-Ion Conducting Oxides $\mathrm{Li}_{3 \mathrm{x}} \mathrm{La}_{2 / 3-\mathrm{x}} \mathrm{TiO}_{3}$ from Fundamentals to Application," Solid State Ionics, Vol. 179, No. 1-6, 2008, pp. 9-15.

[10] S. Stramare, V. Thangadurai and W. Weppner, "Lithium Lanthanum Titanates: A Review," Chemistry of Materials, Vol. 15, No. 21, 2003, pp. 3974-3990. doi: $10.1021 / \mathrm{cm} 0300516$

[11] M.-L. Martínez-Sarrión, L. Mestres, M. Herráiz, O. Maqueda, A. Bakkali and N. Fernández, "Phase Diagram and Impedance Spectroscopy Study of the $\mathrm{La}_{0.5+x-y} \mathrm{Bi}_{\mathrm{y}} \mathrm{Li}_{0.5-3 x^{-}}$ $\mathrm{TiO}_{3}$ System," European Journal of Inorganic Chemistry, Vol. 2002, No. 7, 2002, pp. 1794-1800. doi:10.1002/1099-0682(200207)2002:7<1794::AID-EJIC 1794>3.0.CO;2-\#

[12] M.-L. Martínez-Sarrión, L. Mestres, M. Herráiz, O. Maqueda, N. Fernández and M. F. García, "Synthesis and Electrical Properties of the $\operatorname{Pr}_{0.5+\mathrm{x}-\mathrm{y}} \mathrm{Bi}_{\mathrm{y}} \mathrm{Li}_{0.5-3 \mathrm{x}} \mathrm{TiO}_{3}$ System," European Journal of Inorganic Chemistry, Vol. 2003, No. 13, 2003, pp. 2458-2462. doi:10.1002/ejic.200200657

[13] R. D. Shannon, "Revised Effective Ionic Radii and Systematic Studies of Interatomic Distances in Halides and Chalcogenides," Acta Crystallographica, Vol. 32, No 5, 1976, pp. 751-767.

[14] A. R. West, "Solid State Chemistry and Its Applications," John Wiley \& Sons, Hoboken, 1998.

[15] M. F. García-Sánchez, N. Fernández, M.-L. MartínezSarrión, L. Mestres, M. Herraiz, P. Escribano, E. Cordoncillo and H. Beltrán, "Comparison of the Electrical Properties of the New Conductor $\mathrm{Pr}_{0.5} \mathrm{Bi}_{0.05} \mathrm{Li}_{0.35} \mathrm{TiO}_{3}$ Prepared by Sol-Gel and Ceramic Methods," Physica Status Solidi (b), Vol. 242, No. 9, 2005, pp. 1924-1927. doi: $10.1002 /$ pssb. 200461798

[16] T. Wöhrle, P. Gómez-Romero, T. Fries, K. West, M. R. Palacín and N. Casañ-Pastor, "Sol-Gel Synthesis of the Lithium-Ion Conducting Perovskite $\mathrm{La}_{0.57} \mathrm{Li}_{0.3} \mathrm{TiO}_{3}$. Effect of the Synthesis and Thermal Treatments on the Structure and Conducting Properties," Ionics, Vol. 2, No. 5-6, 1996, pp. 442-445. doi:10.1007/BF02375824

[17] M. F. García, N. Fernández, K. Borrego, M.-L. MartínezSarrión, L. Mestres and M. Herraiz, "Study of the Lithium Insertion and Deinsertion in Perovskite Praseodymium Bismuth Lithium Titanate," Journal of the European Ceramic Society, Vol. 25, No. 5, 2005, pp. 729-734.

[18] S. García-Martín, M. A. Alario-Franco, H. Ehrenberg, J. Rodríguez-Carvajal and U. Amador, "Crystal Structure and Microstructure of Some $\mathrm{La}_{2 / 3-\mathrm{x}} \mathrm{Li}_{3 \mathrm{x}} \mathrm{TiO}_{3}$ Oxides: An Example of the Complementary Use of Electron Diffraction and Microscopy and Synchrotron X-Ray Diffraction to Study Complex Materials," Journal of the American
Chemical Society, Vol. 126, No. 11, 2004, pp. 3587-3596. doi:10.1021/ja0384101

[19] O. I. V'yunov, O. N. Gavrilenko, L. L. Kovalenko, S. A. Chernukhin and L. O. Vasilechko, "Intercalation Processes Influence the Structure and Electrophysical Properties of Lithium-Conducting Compounds Having Defect Perovskite Structure," Russian Journal of Inorganic Chemistry, Vol. 56, No. 1, 2011, pp. 93-98. doi:10.1134/S0036023611010232

[20] N. S. P. Bhuvanesh, O. Bohnké, H. Duroy, M. P. Crosnier-Lopez, J. Emery and J. L. Fourquet, "Topotactic $\mathrm{H}^{+} / \mathrm{Li}^{+}$Ion Exchange on $\mathrm{La}_{2 / 3-\mathrm{x}} \mathrm{Li}_{3 \mathrm{x}} \mathrm{TiO}_{3}$ : New Metastable Perovskite Phases $\mathrm{La}_{2 / 3-\mathrm{x}} \mathrm{TiO}_{3-3 \mathrm{x}}(\mathrm{OH})_{3 \mathrm{x}}$ and $\mathrm{La}_{2 / 3-\mathrm{x}} \mathrm{TiO}_{3-3 \mathrm{x} / 2}$ Obtained by Further Dehydration," Materials Research Bulletin, Vol. 33, No. 11, 1998, pp. 1681-1691. doi:10.1016/S0025-5408(98)00170-6

[21] O. Bohnke, C. Bohnke and J. L. Fourquet, "Mechanism of Ionic Conduction and Electrochemical Intercalation of Lithium into the Perovskite Lanthanum Lithium Titanate," Solid State Ionics, Vol. 91, No. 1-2, 1996, pp. 21-31. doi:10.1016/S0167-2738(96)00434-1

[22] M. F. García-Sánchez, J.-C. M’Peko, A. R. Ruiz-Salvador, G. Rodríguez-Gattorno, Y. Echevarría, F. Fernández-Gutierrez and A. Delgado, "An Elementary Picture of Dielectric Spectroscopy in Solids: Physical Basis," Journal of Chemical Education, Vol. 80, No. 9, 2003, pp. 10621073. doi:10.1021/ed080p1062

[23] A. K. Jonscher, "Dielectric Relaxation in Solids," Chelsea Dielectric Press, London, 1983.

[24] M. F. García-Sánchez, A. Ortiz, G. Santana,. M. Bizarro, J. Peña, F. Cruz-Gandarilla, M. A. Aguilar-Frutis and J. C. Alonso, "Synthesis and Characterization of Nanostructured Cerium Dioxide Thin Films Deposited by Ultrasonic Spray Pyrolysis," Journal of the American Ceramic Society, Vol. 93, No. 1, 2010, pp. 155-160. doi:10.1111/j.1551-2916.2009.03374.x

[25] M. F. García-Sánchez, J. Peña, A. Ortiz, G. Santana, J. Fandiño, M. Bizarro, F. Cruz-Goundarilla and J. C. Alonso, "Nanostructured YSZ Thin Films for Solid Oxide Fuel Cells Deposited by Ultrasonic Spray Pyrolysis," Solid State Ionics, Vol. 179, No. 7-8, 2008, pp. 243-249. doi:10.1016/j.ssi.2008.01.088

[26] T. Talebi, M. Haji and B. Raissi, "Effect of Sintering Temperature on the Microstructure, Roughness and Electrochemical Impedance of Electrophoretically Deposited YSZ Electrolyte for SOFCs," International Journal of Hydrogen Energy, Vol. 35, No. 17, 2010, pp. 9420-9426. doi:10.1016/j.ijhydene.2010.05.079

[27] M.-F. García-Sánchez, N. Fernández, M.-L. MartínezSarrión, L. Mestres, F. Fernández-Gutierrez, G. Santana and R. Ruiz-Salvador, "Separation of Electronic and Ionic Conductivity in Mixed Conductors from the AC Response: Application to $\operatorname{Pr}_{0.56} \mathrm{Bi}_{0.04} \mathrm{Li}_{0.2} \mathrm{TiO}_{3}$," Applied Physics Letters, Vol. 93, No. 3, 2008, 034105. doi:10.1063/1.2959189

[28] D. Jonhson, “Zview for Windows," Scribner Associates, Inc., Charlesville, Virginia, 2005.

[29] M. Itoh, Y. Inaguma, W.-H. Jung, L. Chen and T. Nakamura, "High Lithium Ion Conductivity in the Perovskite-Type Compounds $\mathrm{Ln}_{1 / 2} \mathrm{Li}_{1 / 2} \mathrm{TiO}_{3}(\mathrm{Ln}=\mathrm{La}, \mathrm{Pr}, \mathrm{Nd}$, 
Sm," Solid State Ionics, Vol. 70-71, No. 1, 1994, pp. 203207. doi:10.1016/0167-2738(94)90310-7

[30] Y.-J. Shan, Y. Inaguma and M. Itoh, "The Effect of Elec- trostatic Potentials on Lithium Insertion for Perovskites Oxides," Solid State Ionics, Vol. 79, 1995, pp. 245-251. doi:10.1016/0167-2738(95)00069-I 